\title{
Ecstasy's after-effects
}

Following the retraction of a high-profile paper, the US research agency that supports research on drug abuse needs to ensure its independence from intense political pressure to prove that recreational drugs are harmful.

$\mathrm{t}$ was a pretty peculiar result in the first place. Neuroscientist George Ricaurte and colleagues at the Johns Hopkins School of Medicine in Baltimore, Maryland, reported that they had injected monkeys and baboons with the equivalent of three recreational hits of ecstasy, with shocking consequences. Two of the ten animals died, and nearly all the rest had damage to neurons involved in movement and mood.

It turns out that the researchers had injected the animals with methamphetamine - commonly known as speed — by mistake (see Nature 425, 109; 2003). The team deserves credit for the prompt retraction of its paper in Science. But there remains a bad smell that the American Association for the Advancement of Science (AAAS), which publishes Science, and the National Institute of Drug Abuse (NIDA), which funded the research, have done little to clear up.

The reverberations of the original publication - which was subjected to far more US media coverage than this month's retraction are considerable. The mislabelled bottle that the authors say caused their mistake contained 10 grams of methamphetamine, only about a gram of which was used in that particular study. Ricaurte told Nature that at least one more study will need to be retracted. The rest of the bottle's contents were used in experiments that are as yet unpublished.

The retracted paper left the public with the impression that ecstasy is far more hazardous than it may actually turn out to be. This perception may have influenced the fate of the Reducing Americans' Vulnerability to Ecstasy Act. The act, which was appended to another bill and signed into law in April, holds club owners responsible for drug use on their premises. Critics say it is unlikely to reduce ecstasy use, but may discourage club owners from voluntary measures to protect users, such as cool-off rooms for the dangerous overheating that can occur with ecstasy, as these are tantamount to admission that drug use is going on. The legislation might have passed anyway, even if Ricaurte's study had never been published, but the news certainly lent it urgency.

The impression that low doses of ecstasy, or MDMA, are extremely dangerous - misleadingly borne out by Ricaurte's study, but not by two decades of observing the drug being used — will hamper legitimate research to determine whether MDMA could have useful psychotherapeutic properties. Proponents claim that MDMA can be a powerful adjunct to psychotherapy for conditions such as posttraumatic stress disorder, because it promotes self-awareness. At least three studies of this are now under way in Europe. But funding for such work isn't forthcoming in the United States, and proponents say that part of the blame rests with Ricaurte's now-discredited study.

Another remarkable aspect of this episode is the public endorsement of the study, at the time of its publication, by Alan Leshner, chief executive of the AAAS and former director of NIDA. It isn't clear why an officer of the AAAS should be involved at all in publicly promoting a particular result published in its journal, least of all one whose outcome was questioned at the outset by several experts. The AAAS issued the retraction late in the afternoon on Friday 5 September, resulting in low-key media coverage, which contrasts sharply with the hype surrounding the initial paper.

Some observers have in the past questioned NIDA's ability to maintain its independence in the face of the immense pressures brought to bear by those who stand behind America's interminable 'war on drugs'. Now that Leshner is at the AAAS, he needs to safeguard its independence, rather than pander to the Bush administration's jihad against recreational drug use. It falls to the new director of NIDA, Nora Volkow, to bolster NIDA's reputation. She might start with a thorough public review of the circumstances and participants' roles in one of the more bizarre episodes in the history of drug research.

\section{A necessary setback for world trade}

\section{The world's poorer countries took a stand at Cancún to defend free trade in agriculture.}

W orld trade negotiations have significant implications for many scientists. Bio-prospectors rely on international agreements if they are to scour ecosystems for interesting compounds, for example, and antiretroviral drugs will only be made available to those in need through such agreements. The future of agricultural biotechnology also rests, more or less, in the hands of the World Trade Organization.

On the face of it, the acrimonious collapse of trade negotiations in Cancún, Mexico, on 14 September, represents a setback for these efforts. Although the Convention on Biological Diversity has come into effect, as planned, and temporary arrangements are in place for the supply of antiretrovirals and other medicines to poor countries, both activities would benefit from the successful completion of the current round of trade negotiations by its target date of January 2005.

However, the basis of the collapse leaves room for guarded optimism. The talks crashed because a new alliance of developing countries and agricultural exporters, led by India and Brazil, held their ground. They did so even as wealthy nations taunted them by proposing that new areas, such as government contracting, be opened to free competition, while leaving unaddressed the high trade barriers that exclude farmers in poor countries from rich countries' markets.

These barriers - upheld by Japan on behalf of its rice growers, by the United States for its wealthy cotton growers, among others, and by Europe for most of its agricultural sector - remain the chief impediment to free trade between nations. Every country is entitled to protect its own trade interests, but as long as these barriers remain in place, free trade remains a mirage for most of the world's population.

At Cancún, the poor countries finally said that enough is enough. This position carries a short-term cost: poorer nations will always suffer at the hands of richer ones in bilateral trade negotiations, which is why the trade talks must ultimately succeed. But for now there should be a period of silence from Western politicians on the topic of free trade, until they have garnered the courage to address their own protectionism. 